\title{
A RANDOMISED CONTROLLED TRIAL- COMPARING CEMENTED MODULAR BIPOLAR HEMIARTHROPLASTY WITH CEMENTED TOTAL HIP REPLACEMENT IN FRACTURES OF FEMORAL NECK IN ELDERLY PATIENTS
}

\author{
Tulasidas Bhattacharyya1, Tridip Bharali², Kishore Hazarika33, Rajarshi Roy4, Sidhartha Baruah5, Bikash Agarwal6, Hrishikesh Bharali , \\ Kiran Sonowal ${ }^{8}$
}

${ }_{1}^{1}$ Professor, Department of Orthopaedics, Gauhati Medical College and Hospital.

${ }^{2}$ Resistrar, Department of Orthopaedics, Gauhati Medical College and Hospital.

${ }^{3}$ Resistrar, Department of Orthopaedics, Gauhati Medical College and Hospital.

${ }^{4}$ Resistrar, Department of Orthopaedics, Gauhati Medical College and Hospital.

${ }^{5}$ Resistrar, Department of Orthopaedics, Gauhati Medical College and Hospital.

${ }^{6}$ Resistrar, Department of Orthopaedics, Gauhati Medical College and Hospital.

7Postgraduate Student, Department of Orthopaedics, Gauhati Medical College and Hospital.

${ }^{8}$ Resistrar, Department of Orthopaedics, Gauhati Medical College and Hospital.

\section{BACKGROUND}

ABSTRACT

Femoral neck fractures have remained as 'unsolved fractures' till today due to the high rate of associated complications. In the Indian scenario, the focus is always on femoral head preservation. In the elderly, however, the options in managing femoral neck fractures seem to be more in favour of head sacrificing surgery such as arthroplasty and the procedure may vary from either cemented to uncemented fixation or hemiarthroplasty to total joint replacement. Nevertheless, the 'gold standard' and the most appropriate treatment for these fractures remain controversial.

The purpose of this study was to analyse the outcome of displaced femoral neck fractures in elderly patients who were fit to receive either a hemiarthroplasty using cemented modular (bimodular/bimod) bipolar prosthesis or total hip arthroplasty using a cemented prosthesis in terms of operation time, blood loss and transfusion, duration and cost of hospitalisation, hip joint function, pain relief, post-operative complications, rate of dislocation, revision and mortality.

\section{MATERIALS AND METHODS}

Over a period of 3 years (2013 - 2016), a prospective randomised controlled trial study was carried out for a total of 40 cases of acute fracture of neck of femur in elderly patients, aged more than 65 yrs. attending the OPD and Emergency Department of Orthopaedics, Gauhati Medical College and Hospital. The patients were followed up and were evaluated clinically, radiologically and functionally (using Harris Hip Score).

\section{RESULTS}

In the HRA group, we achieved excellent functional results in $70 \%$ cases and in the THA group we achieved excellent functional results in $90 \%$ cases and there was no statistically significant difference in terms of Harris Hip Score in both the groups.

\section{CONCLUSION}

From our study, we have seen that there is no significant difference in treatment of neck of femur fractures treated with THA and HRA in terms of functional results and intra- and post-operative complication. However, there is a significant difference in intraoperative blood loss between the two types of procedures.

\section{KEYWORDS}

Fracture Neck of Femur, Elderly, Displaced, Cemented Modular Hemiarthroplasty vs Cemented Total Hip Arthroplasty, Randomised Controlled Trial.

HOW TO CITE THIS ARTICLE: Bhattacharyya T, Bharali T, Hazarika K, et al. A randomised controlled trial- comparing cemented modular bipolar hemiarthroplasty with cemented total hip replacement in fractures of femoral neck in elderly patients. J. Evolution Med. Dent. Sci. 2017;6(79):5607-5614, DOI: 10.14260/jemds/2017/1217

\section{BACKGROUND}

Femoral neck fractures have remained as 'unsolved fractures'1,2 till today due to the high rate of associated

'Financial or Other Competing Interest': None.

Submission 18-08-2017, Peer Review 19-09-2017,

Acceptance 25-09-2017, Published 30-09-2017.

Corresponding Author:

Dr. Tridip Bharali,

C/o. Kumud Bharali,

House No. 5, Milijuli Path,

Rupnagar East, Guwahati-781032,

Kamrup Metro, Assam.

E-mail: tridipbharali69@gmail.com

DOI: $10.14260 /$ jemds $/ 2017 / 1217$

\section{(c) (i) $\$$}

complications, which include non-union and avascular necrosis of the femoral head even after use of best method of fixation devices.

It is a common skeletal injury occurring with trivial trauma in the osteoporotic bone of elderly patients, especially in females. The management started with closed reduction and immobilisation in POP hip spica in the early part of $20^{\text {th }}$ century. ${ }^{3}$ High incidence of non-union, bed sores and respiratory complications led to condemnation of plaster and exploration of other methods like closed reduction and internal fixation. The initial fixation devices failed to produce compression at fracture site and also could not neutralise the rotatory forces and shearing strain at the fracture site. 
Advent of CT scan explained the fracture geometry regarding posterior comminution and loss of position during time of fixation. The use of three partially threaded cancellous screws is probably the best available method of fixation till date. The presentation at different ages poses different problems related to the management, the burning issues being fixation failure in osteopenic bone of the elderly, marked displacement of fragments with posterior comminution, disruption of blood supply and a higher incidence of avascular necrosis (AVN). ${ }^{3}$

Whether fractures of the femoral neck in elderly patients are treated with internal fixation, hemiarthroplasty or total hip replacement (THR), should be determined by the degree of fracture displacement, the patient's age, functional demands and risk profile, such as level of cognitive function and degree of physical fitness. ${ }^{4,5}$ However, the surgical treatment of displaced femoral neck fractures differs from the treatment of many other hip fractures because the available treatment modalities, internal fixation (IF), hemiarthroplasty (HA) and total hip replacement (THR) differ in surgical impact, complications and long-term outcomes. Consequently, each modality has its own unique characteristics, advantages and disadvantages.

In the Indian scenario, the focus is always on femoral head preservation. In the elderly, however, the options in managing femoral neck fractures seem to be more in favour of head sacrificing surgery such as arthroplasty and the procedure may vary from either cemented to uncemented fixation or hemiarthroplasty to total joint replacement. ${ }^{3}$ Main reason being health of the patient would not permit a second operation and financial constraints.

The goal of treatment is to return the patient to his or her premorbid status of function. Nevertheless, the 'gold standard' and the most appropriate treatment for these fractures remain controversial.

Femoral neck fracture in the elderly poses a problem of poor bone quality and co-morbid medical conditions. Hagino et al evaluated the prognosis among different age groups in elderly patients aged 65 years and above treated for hip fractures. ${ }^{6} \quad$ Replacement arthroplasty, either hemiarthroplasty (Austin Moore, Thompson's or Bipolar prosthesis) or total hip replacement was found to be ideally suitable for the elderly population as a primary procedure to tackle the problem of fixation failure, non-union and AVN.

There appears to be a consensus among orthopaedic surgeons that unipolar or bipolar hemiarthroplasty is the preferred treatment for displaced intracapsular fractures in elderly patients with low functional demands. ${ }^{7}$ THA is advocated in cases where life expectancy is significant and when acetabular disease is present. For older people, bipolar arthroplasty may be a better option. Specific indications exist for cemented and cementless replacements. ${ }^{3}$ It is almost certain that better short-term clinical and functional outcomes can be obtained from cemented femoral fixation than those from the uncemented. ${ }^{8}$ At least the cemented group is equal, if not superior to the uncemented group. However, for the relatively healthy, active and mentally alert elderly patient, treatment is still controversial. ${ }^{7}$ There is inadequate evidence to support the choice between different types of arthroplasty. There seemed to be an advantage for THR over bipolar hemiarthroplasty, especially at longer followup, but various authors recommended further trials to verify it. ${ }^{9}$
The purpose of this study was to analyse the outcome of displaced femoral neck fractures in elderly patients, who are fit to receive either a hemiarthroplasty using cemented modular (bimodular/bimod) bipolar prosthesis or total hip arthroplasty using a cemented prosthesis in terms of operation time, blood loss and transfusion, duration and cost of hospitalisation, hip joint function, pain relief, postoperative complications, prosthesis loosening, rate of dislocation, revision and mortality.

\section{MATERIALS AND METHODS}

Over a period of 3 years (2013 - 2016), a prospective randomised controlled trial study was carried out for a total of 40 cases of acute fracture neck of femur in elderly patients aged more than 65 yrs. attending the OPD and Emergency Department of Orthopaedics, Gauhati Medical College and Hospital who meet the inclusion and exclusion criteria. This study was cleared by the Ethical Committee of Gauhati Medical College, Guwahati. The sample size was decided as per the admission rate and by surveying the average number of acute neck of femur fracture patients within the said age group posted for replacement surgeries in the last 3 years before starting our study as documented in the operation registration books of orthopaedics operation theatre in our institute. In a pilot study the mean surgical time in HRA group, 71.3 minutes with a standard deviation of 25 minutes. To detect a difference of 25 minutes, which was a priority decided to be clinically important; 16 patients in each group is necessary to achieve a power of $80 \%$ with alpha of $5 \%$. Thus, considering attrition rate of at least $15 \%$ a sample of 20 in each group was taken.

All patients above 65 yrs. with fresh neck fractures $(<2$ weeks) and who were able to walk prior to the fracture were included in the study.

Patients aged $<65$ yrs., $>80$ yrs., duration of injury $>2$ weeks with active infection, advanced arthritis or with a pathological fracture were excluded from the study. All the cases were followed up for a minimum period of twelve months.

Preoperatively, Buck's traction with appropriate weight was applied to the fractured lower limb with an aim of relieving pain, preventing shortening and to reduce unnecessary movements of the injured limb. On receiving the patient, initial symptomatic treatment and a detailed history of the patient was taken.

The initial radiographs included antero-posterior view of the affected hip joint of pelvis with both hips were taken for all the patients, keeping the fractured limb in $15^{\circ}$ internal rotation to bring the neck parallel to $\mathrm{x}$-ray film.

After assessment by an anaesthetist for fitness for operation, randomisation was done using the plan generated from the website www.randomization.com to allocate the patient into one of the following two treatment models-

1. Hemi replacement arthroplasty using cemented modular bipolar prosthesis (20 patients).

2. Total hip arthroplasty using cemented prosthesis (20 patients).

For all our patients, posterior approach was used. The modular femoral component (DePuy) with a $28-\mathrm{mm}$ head was used in all cases with either a bipolar Hastings head or with an OGEE (DePuy/Johnson and Johnson) acetabular component. The same cementing technique was used in both groups. A distal restrictor and a proximal seal were used when cementing the femoral component and a cement 
pressuriser was used when cementing the acetabular component.

Intravenous antibiotics (Ceftriaxone with Sulbactam 1.5 gm and Amikacin $500 \mathrm{mg}$ ) were administered twice daily for the first 3 days and then shifted to Oral Cefuroxime $500 \mathrm{mg}$ twice daily for the next 7 days. Patients were taught quadriceps strengthening exercises, weight bearing with support and leg dangling by the side of the bed as soon as the pain subsides to a tolerable limit. The patients were regularly followed up at 6 weeks, 3, 6, 9, 12, 24 and 36 months and were evaluated clinically, radiologically and functionally (using Harris Hip Score). The statistical analysis was done by using unpaired ' $\mathrm{t}$ ' test for continuous numerical values and chi-square test for categorical values and the tables were analysed using GraphPad InStat 3 software.

\section{RESULTS}

1. The average age of the patients in our series was 70.0 years ( $\mathrm{SD}=3.63$ years) with most patients between 65 70 years. Maximum age was 76 years and minimum age was 66 years with mean age of 69.58 years $(\mathrm{SD}=3.8$ years) in males and 70.62 years $(S D=3.5$ years) in females.

2. The fractures were more commonly encountered on the right side (55\%). There were no bilateral cases.

3. All of the patients had minimal trauma, most of them slipped and fell down on flat ground or in bathroom and were not able to walk or stand.

4. Associated disorders like Diabetes Mellitus, Hypertension, Chronic Obstructive Pulmonary Disease and Anaemia were present in about 28 cases (70\%). The patients were taken up for surgery as soon as they became medically fit for the surgical procedure.

5. Most of the cases (40\%) were operated in $2-7$ days following injury. The mean time interval between surgery and trauma was 4.5 days ( 2 - 12 days).

6. The average operative time of surgery in both the groups combined was 81.95 (62 - $120 \mathrm{~min}$ ) with a standard deviation of 20.49. The mean operative time of surgery in the group HRA using MODULAR prosthesis was 71.3 mins. (62 - 101 mins.) with standard deviation of 9.28 (95\% confidence interval 63.23 - 79.37). The mean operative time of surgery in group using THA was 92.6 mins. (85 - 120 mins.) with standard deviation of 8.29 (95\% confidence interval 85.23 - 101.97). On statistical analysis comparing the two groups, the p-value was found to be 0.67 (unpaired ' $\mathrm{t}$ ' test), which is statistically insignificant. This indicates that there is no statistically significant difference between the two groups in relation to duration of surgery.

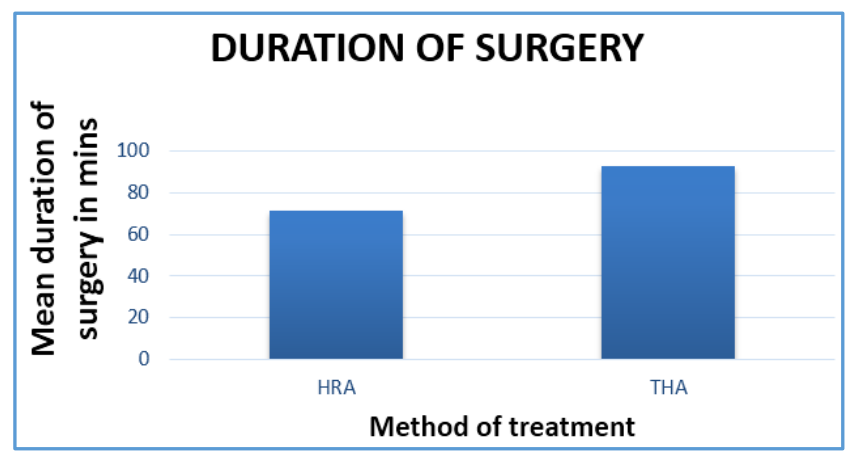

Figure 1. Bar Diagram showing Average Operative Time in HRA and THA
7. Closed suction was used in all the cases and the amount of blood collected in the suction jar minus the amount of saline use was calculated to find the rough estimate of the amount of blood loss in each case. The average intraoperative blood loss in our study was $407.5 \mathrm{~mL}$ (standard deviation 90.9). The average blood loss in the HRA group was found to be $280.0 \mathrm{~mL}$ (standard deviation- 100.55 , 95\% confidence limit from 208.07 to 351.93). The average blood loss in the THA group was found to be $485.0 \mathrm{~mL}$ (standard deviation 229.79, 95\% confidence limit from 370.63 to 699.37). The above two values were tested statistically by unpaired ' $t$ ' test. The $p$ value was $<0.0001$, which is statistically significant. This indicates that there exists a statistically significant difference between the two groups in relation to intraoperative blood loss, which may affect the outcome. However, no hypovolaemic shock in the patients were encountered in our study.

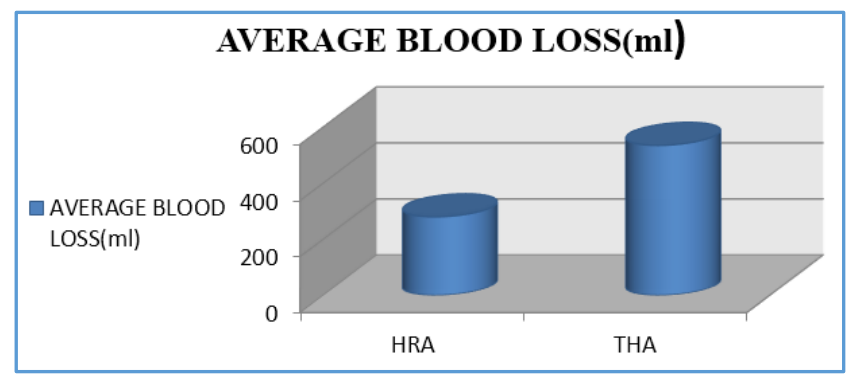

Figure 2. Bar Diagram showing Average Blood Loss during Operation

8. Complications: No general complication from surgery like septicaemia, deep vein thrombosis, pulmonary emboli, CVA, etc. was encountered. There was also no reported case of dislocation in our study. No loosening of implant, late infection and mortality was recorded in our series. However, in the HRA group we had two cases of bed sore of superficial grade 1 , which responded to use of pneumatic bed and dressing. The bed sore was seen in patients with prolonged immobilisation secondary to delay in surgery due to comorbidities like cachexia, diabetes or anaemia. Lefaivre et al ${ }^{10}$ showed that when the surgery was delayed for more than 24 hrs., it was significantly related to increase in pressure sore. Grimes et $\mathrm{al}^{11}$ showed that the risk of decubitus ulcer increased as the surgery was delayed for more than $96 \mathrm{hrs}$.

In the THA group, we had one case of superficial infection which responded to antibiotics with regular dressing. Blomfeldt et al,12 Van den Bekerom et $\mathrm{al}^{13}$ in their study also reported superficial infection in either groups. The difference between the groups was not statistically significant.

\begin{tabular}{|c|c|c|}
\hline \multirow{2}{*}{ Clinical Studies } & \multicolumn{2}{|c|}{ Superficial Infection } \\
\hline & HRA & THA \\
\hline Blomfeldt et al ${ }^{12}$ & $3.3 \%$ & $3.3 \%$ \\
\hline van den Bekerom et al ${ }^{13}$ & $2.1 \%$ & $1.7 \%$ \\
\hline Maini PS et al ${ }^{14}$ & 4.1 & - \\
\hline Our study & 0 & $5 \%$ \\
\hline \multicolumn{3}{|c|}{ Table 1. Percentage of Infection in Various Studies } \\
\hline
\end{tabular}


9. Harris Hip Scoring system was used to evaluate the functional result in our study. Patients who had a normal range of motion, minimum limp, no pain and who rarely used a cane were graded as having excellent result (score 90 -100). Patients with score 80 - 89 were graded good result. Those with score 70 - 79 were graded fair and those with score less than 70 were graded as poor.

At 12 months followup in the HRA group, 14 patients $(70 \%)$ had excellent results and 6 patients $(30 \%)$ had good results, whereas in the THA group 18 patients $(90.0 \%)$ had excellent results and 2 patients $(10.0 \%)$ had good result.

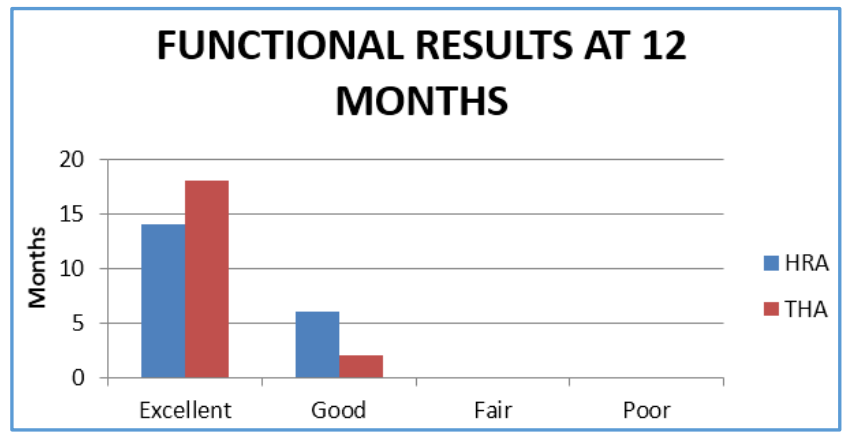

Figure 3. Bar Diagram showing Functional Results in HRA and THA Group

10. As per the Harris hip scoring system, the pain component was measured and accordingly in the HRA group 15 patients (75\%) had no pain; 3 patients (15\%) had slight pain and 2 patients had mild pain (10\%); whereas in the THA group 18 patients (90\%) had no pain and 2 patients $(10 \%)$ had slight pain

11. In the HRA group 16 patients (80\%) had no limp; 4 patients $(20 \%)$ had slight limp; whereas in the THA group 18 patients $(90 \%)$ had no limp, 2 patients $(10 \%)$ had slight limp.

12. In the HRA group 12 patients $(60 \%)$ climbed the stairs without support; 8 patients (40\%) climbed the stairs with support of railing; whereas in the THA group 16 patients $(80.0 \%)$ climbed the stairs without support; 4 patients $(20.0 \%)$ climbed the stairs with support of railing.

13. In the HRA group 14 patients were able to sit comfortably in ordinary chair for one hour; 6 patients were able to sit on high chair for 30 minutes; whereas in the THA group 16 patients $(80.0 \%)$ were able to sit comfortably in ordinary chair for one hour; 4 patients (20.0\%) were able to sit on high chair for 30 minutes. On gradual followup, pain, limp and climbing stairs improved in the patients.

14. Range of Movements

\section{a) Flexion}

The mean range of hip flexion in the HRA group was found to be 108 degrees, (standard deviation 11.35). The worst flexion range was found to be 90 degrees. The mean range of hip flexion in the THA group was found to be 109 degrees, (standard deviation 8.76). On statistical analysis comparing the two groups the p-value was found to be 0.254 , which is statistically insignificant.

\section{b) Abduction}

The mean range of abduction in the HRA group was found to be 41.5 degrees (standard deviation 2.42), while the mean range of abduction in the THA group was also found to be 42 degrees (standard deviation 2.58). On statistical analysis comparing the two groups the p-value was found to be 0.997 , which is statistically insignificant.

\section{c) Adduction}

The mean range of adduction in the HRA group was found to be 38.5 degrees, while in the THA group the mean range of adduction was 38.5 degrees. On statistical analysis comparing the two groups the pvalue was found to be 1.000 , which is statistically insignificant.

\section{d) Internal Rotation}

The mean range of internal rotation in the HRA group was found to be 42 degrees (standard deviation 2.58), while in the THA group the mean range of internal rotation was 42.5 degrees (standard deviation 2.63). On statistical analysis comparing the two groups the $\mathrm{p}$-value was found to be 0.997 , which is statistically insignificant.

\section{e) External Rotation}

The mean range of external rotation in the HRA group was found to be 39.5 degrees (standard deviation 3.69), while the mean range of external rotation in the THA group was found to be 42.0 degrees (standard deviation 2.58). On statistical analysis comparing the two groups the p-value was found to be 0.996 , which is statistically insignificant.

15. The average time of partial weight bearing was 1.65 days with standard deviation of 0.81 .

16. The average time of full weight bearing in the group of HRA was 1.9 days with standard deviation of 0.88 , while in the group of THA 1.4 days with standard deviation of 0.69 . However, on statistical analysis it was found that there was no significant difference in both the groups in terms of time for partial weight bearing (p- 0.985 with 9 degrees of freedom).

17. All cases were followed up according to pre-fixed protocol with followup of $6,9,12$ months and subsequently at 2 and 3 yrs. The average followup was 24.4 months with a standard deviation of 2.56. The maximum followup in our study was 36 months. The average followup in the HRA group was 22 months and in THA group was 23.8 months and the difference was statistically not significant (p-0.977).

\section{DISCUSSION}

Despite the improvements in the understanding of the fracture, implant designs, surgical technique and after care, the dilemma of the right choice of treatment for the right patient remains. The marked improvements in the socioeconomic conditions and the quality of life have resulted in improvement in life expectancy, as also to a rise in the incidence of fracture neck of femur. 
While our study was limited to 40 cases, Blomfeldt $\mathrm{R}$ et al $^{12}$ studied 120 cases, MPJ Van den Bekerom et al ${ }^{13}$ studied 252 cases and Lee et al ${ }^{15}$ studied 126 cases. This is due to the fact that this study was limited to a very short duration. Also, financial constraints and unawareness of this procedure to the patient limited the number of patients for this study.

The average age incidence in our study was 70.0 years with a range of 65 to 80 years. Our study was comparable to other studies as mentioned in the table.

\begin{tabular}{|c|c|}
\hline Clinical Studies & Mean Age in Years \\
\hline Blomfeldt et al $^{12}$ & 81 y (70-90) \\
\hline Gupta et al $^{16}$ & 60 y (50-80) \\
\hline Van den Bekerom et al $^{13}$ & 81.1 y (70.2-95.6) \\
\hline Keating JF $^{9}$ & 75.4 y (68-82) \\
\hline Our Study & 70.0 y \\
\hline Table 2. Age Distribution in Various Comparable Studies
\end{tabular}

In the HRA group about 16 patients $(80 \%)$ got operated within 7 days of admission; 4 patients (20\%) got operated between 7 - 14 days of admission; whereas in the THA group 14 patients (70\%) got operated within 7 days of admission; 6 patients (30\%) got operated between 7 - 14 days of admission. In neither of the groups did the surgery got delayed more than 14 days from admission.

The reason for delay was the associated morbidity with the patient like diabetes, hypertension, anaemia and COPD. For these patients, a longer period of pre-operative evaluation and optimisation was required. Novack et al $^{17}$ showed the length of surgery delay had a gradual effect on increasing mortality of both short-term amid long-term. Majumdar et $\mathrm{al}^{18}$ reported no independent association between timing of surgery and mortality. Evidences in the literature regarding the effect of delay to surgery on mortality are conflicting and there is no conclusive evidence. Although, there is no solid evidence that early surgery would improve mortality, there is widespread evidence in the literature that other outcomes including morbidity, the incidence of pressure sores and the length of hospital stay could be improved by shortening the waiting time of hip fracture surgery. This probably holds good if head preserving surgery is attempted. Early surgery can bring better pain relief. Hence, it is still apt to treat these patients as soon as their bodies meet the basic anaesthetic requirements. In the HRA group, the mean duration of surgery ranged from 62 - 101 minutes (mean 71.3 mins.) with a mean amount of blood loss of $280 \mathrm{~mL}$, whereas in the THA group the mean duration of surgery ranged from 85 - 120 minutes (mean 92.6 mins.) and mean amount of blood loss being $485.0 \mathrm{~mL}$. Surgical time (71.3 minutes versus 92.6 minutes) and blood loss (280 mL versus $485 \mathrm{~mL}$ ) was greater for the THA group. The difference between the groups was significant $(\mathrm{p}<0.0001)$.

Blomfeldt $\mathrm{R}$ et $\mathrm{al}^{12}$ reported duration of 78 mins with a blood loss of $320 \mathrm{~mL}$ in HRA group and 102 mins. with a blood loss of $460 \mathrm{~mL}$ in THA group. The difference between the groups were significant $(\mathrm{p}<0.001)$. Van den Bekerom et $\mathrm{al}^{13}$ and Zhao $\mathrm{Y}^{19}$ in their study recorded blood loss and surgical time, which was found to be lower in case of HRA compared to THA.

\begin{tabular}{|c|c|c|c|c|}
\hline \multirow[t]{2}{*}{ Clinical Studies } & \multicolumn{2}{|c|}{$\begin{array}{l}\text { Mean Amount of } \\
\text { Blood Loss in } \\
\text { Millilitres }\end{array}$} & \multicolumn{2}{|c|}{$\begin{array}{l}\text { Mean Duration of } \\
\text { Surgery in Minutes }\end{array}$} \\
\hline & HRA & THA & HRA & THA \\
\hline Blomfeldt $\mathrm{R}$ et al ${ }^{12}$ & 320 & 460 & 78 & 102 \\
\hline Giannini et al 20 & 380 & 460 & 71 & 76.7 \\
\hline Our Study & 280 & 485 & 71.3 & 92.6 \\
\hline $\begin{array}{r}\text { Table } 3 . \\
\text { of }\end{array}$ & $\begin{array}{l}\text { an } B \\
\text { ery }\end{array}$ & $\begin{array}{l}\text { sss a } \\
\text { ous }\end{array}$ & $\begin{array}{l}\text { Duratio } \\
\text { dies }\end{array}$ & \\
\hline
\end{tabular}

MPJ Van den Bekerom et al ${ }^{13}$ and Zhao $\mathrm{Y}^{19}$ in their study recorded higher dislocation rate in THA compared to HRA. Blomfeldt et $\mathrm{al}^{12}$ did not report any dislocation in either group. In our study, there was no incidence of any dislocation. We could probably prevent this complication by using a long knee brace keeping the limb in abduction for first $48 \mathrm{hrs}$. in all our cases.

In our study, there was no statistical difference in the pain scoring ( $p$ value $=0.322)$ between the HRA and THA groups, which matches with the other similar studies like Van den Bekerom et $\mathrm{al}^{13}$ where mean HHS pain was 37.5 and 40.0 for HRA and THA respectively. But Blomfeldt et al ${ }^{12}$ reported mean HHS pain at 12 months was 39.1 and 43.1 for HRA and THA respectively $(p<0.001)$. Macaulay et $a^{21}$ found that THA patients had significantly less pain than hemiarthroplasty patients $(54.8 \pm 7.9$ vs $44.7 \pm 10.5, \mathrm{P}=.04)$. Dorr et al 22 showed that no difference was found in the level of pain, ambulation or aids required between the THA group and the hemiarthoplasty group, except for active community ambulators who demonstrated decreased endurance capability when treated with hemiarthroplasty.

\begin{tabular}{|c|c|c|}
\hline \multirow{2}{*}{ Clinical Study } & \multicolumn{2}{|c|}{ Results of Pain } \\
\hline & HRA & THA \\
\hline Van den Bekerom et al ${ }^{13}$ & 37.5 & 40.0 \\
\hline Blomfeldt et al ${ }^{12}$ & 39.1 & 43.1 \\
\hline Our Study & 38.2 & 40.6 \\
\hline \multicolumn{3}{|c|}{ Table 4. Results of Pain in Various Studies } \\
\hline
\end{tabular}

The results in our study did not show any statistical difference in the evaluation of limp $(P=0.088)$, ability to walk $(\mathrm{P}=0.439)$ and use of walking aids $(\mathrm{P}=0.270)$ which matches with other similar studies like Van den Bekerom et al ${ }^{13}$ reported no difference in function in two groups after 12 months. Baker et $\mathrm{al}^{23}$ reported better function in THA patients compared to HRA patients $(p=0.039)$. Blomfeldt et $\mathrm{al}^{12}$ in their study reported mean HHS function score for HRA and THA as 31.6 and 35.3 respectively after 12 months. The results were significant $(\mathrm{p}<0.037)$.

In our study, the HRA group mean HHS ROM was found to be 2.005 and for THA group was 1.9. In Blomfeldt et al ${ }^{12}$ study, the mean HHS ROM for HRA and THA group was 4.7 and 4.7 respectively $(\mathrm{p}=0.435)$.

\begin{tabular}{|c|c|c|}
\hline Clinical Studies & HRA & THA \\
\hline Blomfeldt et al 12 & 4.7 & 4.7 \\
\hline Our Study & 2.005 & 1.9 \\
\hline \multicolumn{2}{|c|}{ Table 5. Mean Range of Movement } \\
Score in Comparable Study \\
\hline
\end{tabular}




\section{Total Functional Result at 12 Months}

In the HRA group, 14 patients $(70 \%)$ had excellent results and 6 patients (30\%) had good results, whereas in the THA group 18 patients (90.0\%) had excellent results and 2 patients $(10.0 \%)$ had good result. There was no statistically significant difference in the functional outcome $(p=0.9808)$ between the two groups in our study. The total functional results in terms of sitting on chair, independent walking and climbing stairs improved at 24 and 36 months followup. And our study results match most of the other similar studies mentioned below.

One year Harris Hip score results were equivalent and there were no differences in ability to walk, use of analgesics or place of living in both the groups.

Blomfeldt $\mathrm{R}$ et $\mathrm{al}^{12}$ in their study found the mean Harris hip score difference in favour of the THR group at both reviews and increased with time. MPJ Van den Bekerom et al ${ }^{13}$ reported after one and five years followup the results of bipolar hemiarthroplasty are similar to THR for the treatment of patients aged $\geq 70$ years with displaced femoral fractures. Baker et $\mathrm{al}^{23}$ in 2006 showed superior short-term results in their comparative study in cases operated by total hip arthroplasty.

\begin{tabular}{|c|c|c|}
\hline \multirow[t]{2}{*}{ Clinical Studies } & \multicolumn{2}{|c|}{$\begin{array}{l}\text { Mean Harris Hip Functional } \\
\text { Scoring }\end{array}$} \\
\hline & HRA & THA \\
\hline Blomfeldt et al 12 & 79.4 & 87.2 \\
\hline Van den Bekerom et al ${ }^{13}$ & 73.9 & 76 \\
\hline Giannini S20 & 75.5 & 80.7 \\
\hline Macaulay et al21 & $\begin{array}{c}65.1 \pm 18.1 \\
\text { (WOMAC score) }\end{array}$ & $\begin{array}{c}81.8 \pm 10.2 \\
\text { (WOMAC score) }\end{array}$ \\
\hline Our Study & 91.7 & 93.1 \\
\hline \multicolumn{3}{|c|}{$\begin{array}{c}\text { Table 6. Showing Mean Harris Hip Scores at } 12 \\
\text { Months in the Comparable Clinical Studies }\end{array}$} \\
\hline
\end{tabular}

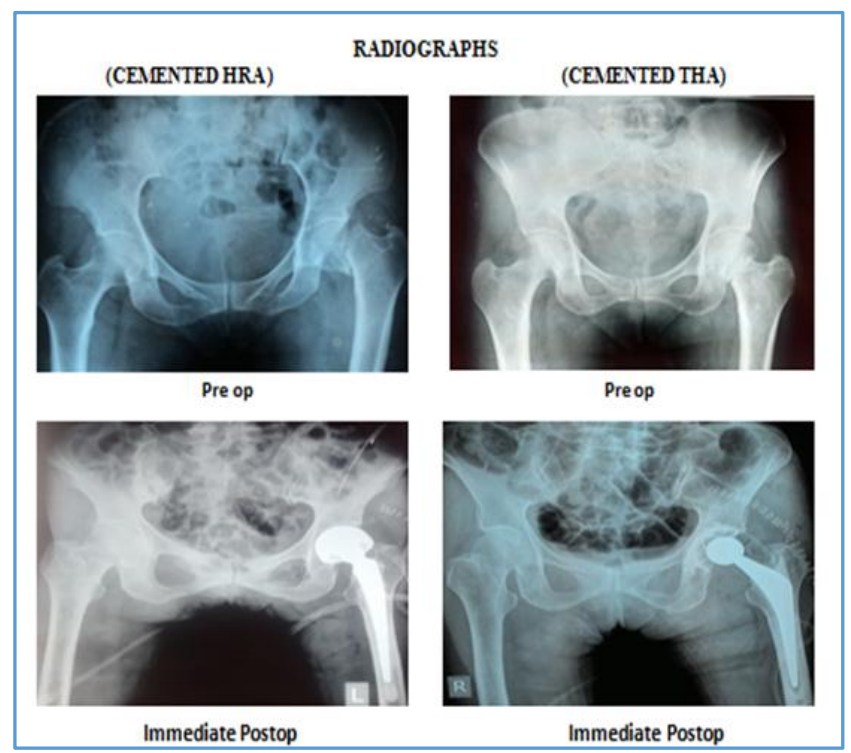

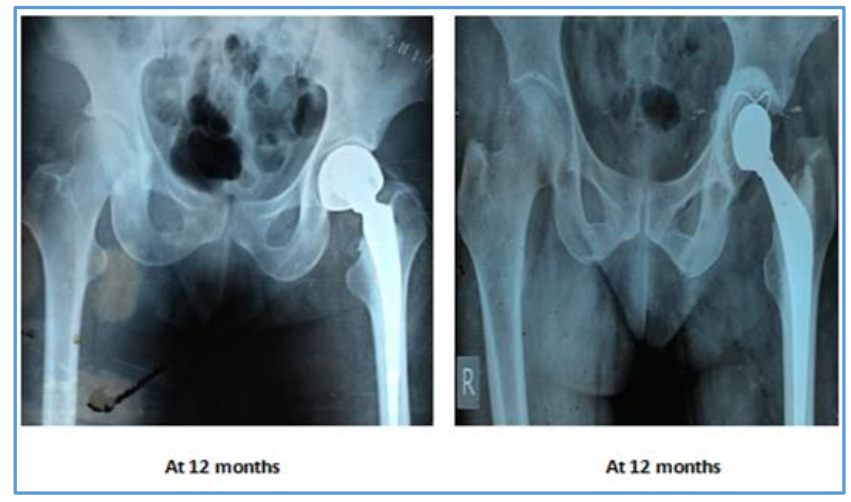

Functional Outcome of THR Patient after 36 Months
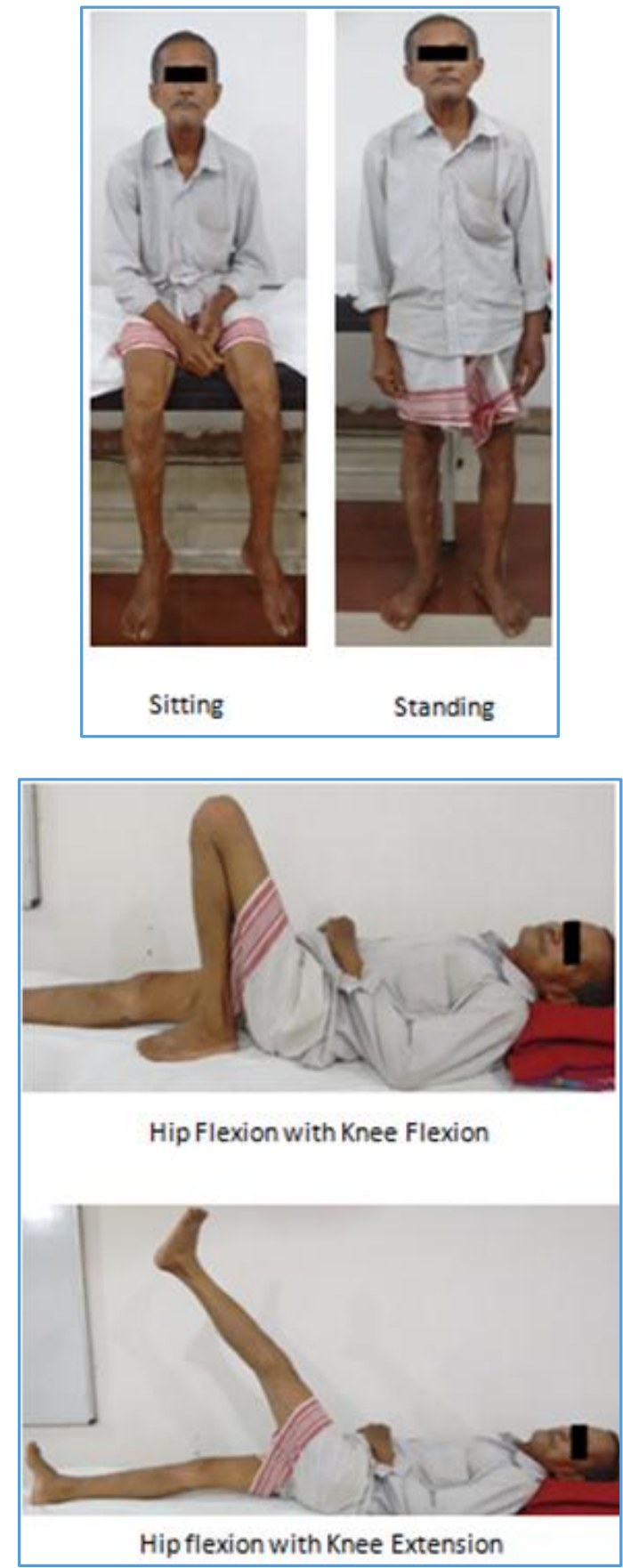


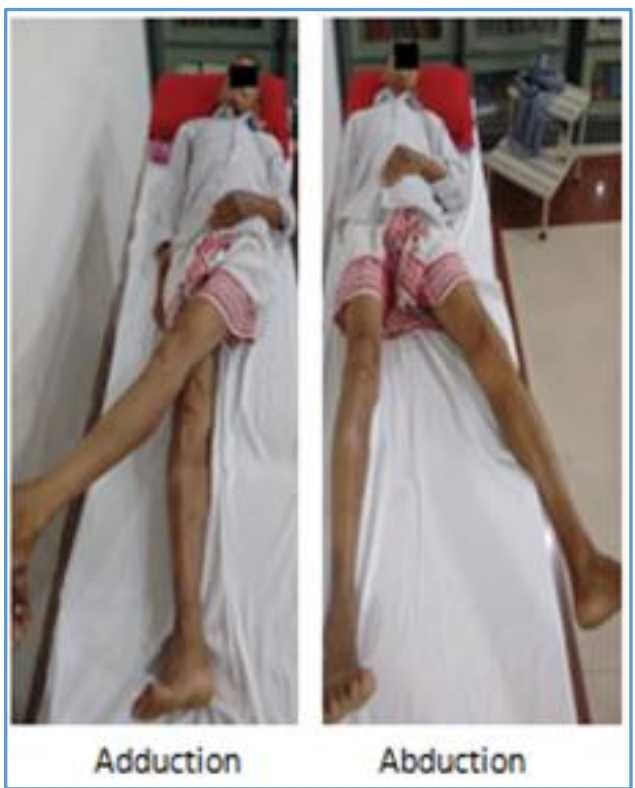

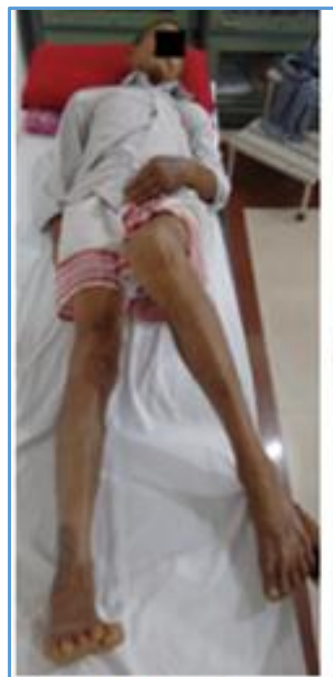

Internal Rotation

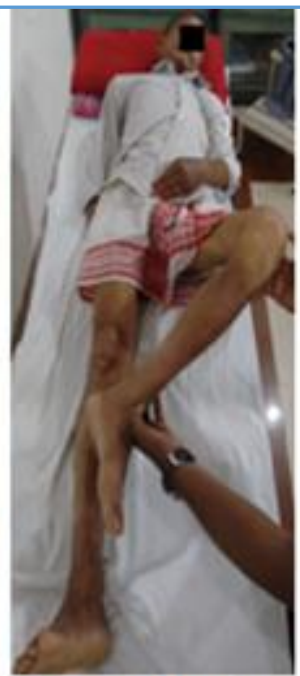

External Rotation

\section{Functional Outcome of HRA Patient after 36 Months}

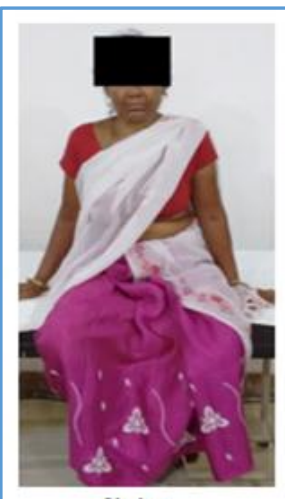

Sitting

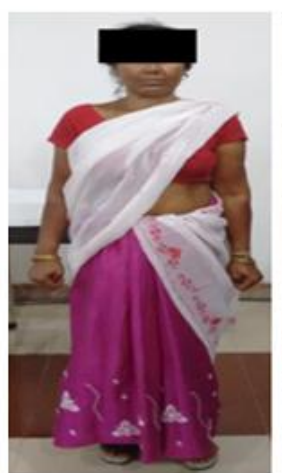

Standing

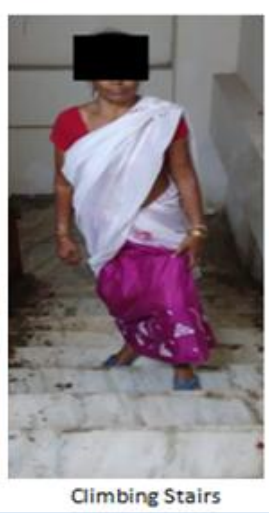

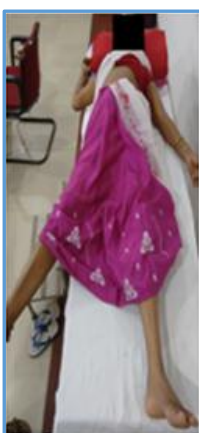

Abduction

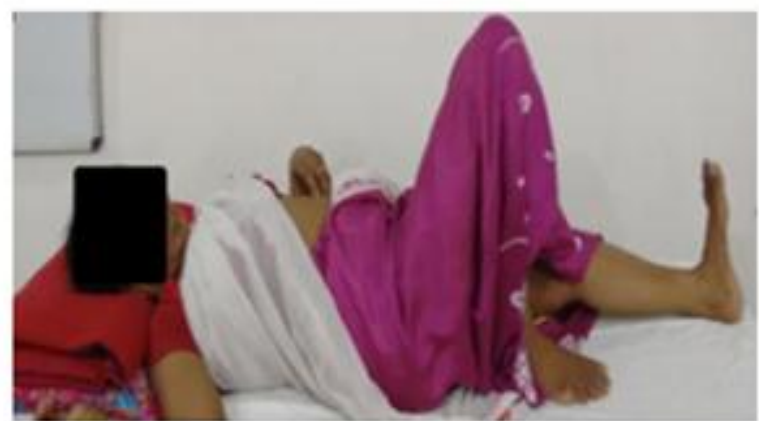

Hip Flexion with Knee Flexion

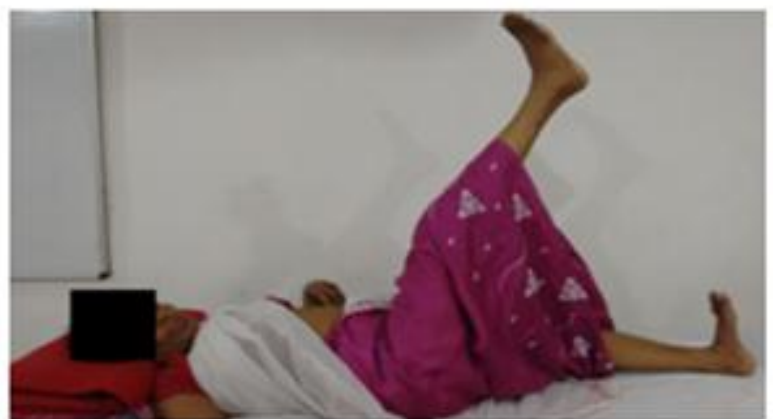

Hip Flexion with Knee Extension

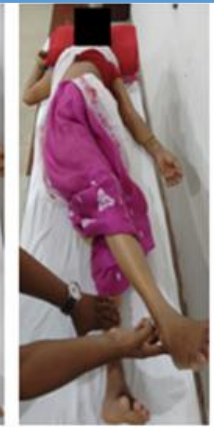

Adduction

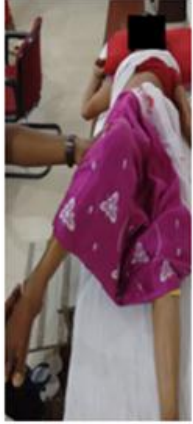

Internal Rotation

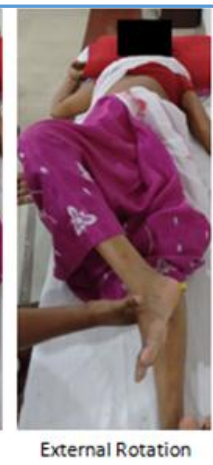

\section{ABBREVIATIONS}

HRA: Hemiarthroplasty, THA: Total hip arthroplasty, POP: Plaster of Paris, HTN: Hypertension, ROM: Range of Movement, RTA: Road traffic accident, AVN: Avascular necrosis, COPD: Chronic obstructive airway disease, HHS: Harris Hip Score.

\section{CONCLUSION}

From our study, we have seen that both hemiarthroplasty and total hip arthroplasty are good treatment options for treatment of displaced femoral neck fractures in elderly. There is no significant difference in treatment of neck of femur fractures treated with THA and HRA in terms of functional results and intra- and post-operative complications. However, there is a statistically significant difference in intra-operative blood loss between the 2 types of procedures. The increased blood loss and longer operating time associated with THR did not increase the number of general complications or the mortality rate. Timing of surgery does not have any significant effect on final outcome. 


\section{REFERENCES}

[1] Parker M. Fractured neck of femur-solving the unsolved fracture. Trauma 2000;2(1):33-41.

[2] Dickson JA. The "unsolved" fracture' a protest against defeatism. J Bone Joint Surg Am 1953;35-A(4):805-22.

[3] Sandhu HS, Dhillon MS, Jain AK. Femoral neck fractures. IJO 2008;42(1):1-2.

[4] Masson M, Parker MJ, Fleischer S. Internal fixation versus arthroplasty for intracapsular proximal femoral fractures in adults. Cochrane Database Syst Rev 2003;(2):CD001708.

[5] Tidermark J. Quality of life and femoral neck fractures. Acta Orthop Scand Suppl 2003;74(309):1-42.

[6] Hagino T, Maekawa S, Sato E, et al. Prognosis of proximal femoral fracture in patients aged 90 years and older. J Orthop Surg (Hong Kong) 2006;14(2):1226.

[7] Bhandari M, Devereaux PJ, Tornetta P, et al. Operative management of displaced femoral neck fractures in elderly patients. An international survey. J Bone Joint Surg Am 2005;87(9):2122-30.

[8] Ni GX, Lu WW, Chiu KY, et al. Cemented or uncemented femoral component in primary total hip replacement? A review from a clinical and radiological perspective. J Orthop Surg 2005;13(1):96-105.

[9] Keating JF, Grant A, Masson M, et al. Randomized comparison of reduction and fixation, bipolar hemiarthroplasty, and total hip arthroplasty. Treatment of displaced intracapsular hip fractures in healthy older patients. J Bone Joint Surg Am 2006;88(2):249-60.

[10] Lefaivre KA, Macadam SA, Davidson DJ, et al. Length of stay, mortality, morbidity and delay to surgery in hip fractures. J Bone Joint Surg Br 2009;91(7):922-7.

[11] Grimes JP, Gregory PM, Noveck H, et al. The effects of time-to-surgery on mortality and morbidity in patients following hip fracture. Am J Med 2002;112(9):702-9.

[12] Blomfeldt $R$, Törnkvist $H$, Eriksson $K$, et al. A randomised controlled trial comparing bipolar hemiarthroplasty with total hip replacement for displaced intracapsular fractures of the femoral neck in elderly patients. J Bone Joint Surg $\mathrm{Br}$ 2007;89(2):160-5.

[13] van den Bekerom MP, Hilverdink EF, Sierevelt IN, et al. A comparison of hemiarthroplasty with total hip replacement for displaced intracapsular fracture of the femoral neck: a randomised controlled multicentre trial in patients aged 70 years and over. J Bone Joint Surg Br 2010;92(10):1422-8.
[14] Maini PS, Navin T, Nijhawan VK, et al. Results of cemented bipolar hemiarthroplasty for fracture of the femoral neck-10 year study. Indian Journal of Orthopaedics 2006;40(3):154-6.

[15] Lee BP, Berry DJ, Harmsen WS, et al. Total hip arthroplasty for the treatment of an acute fracture of the femoral neck: long-term result. J Bone Joint Surg Am 1998;80(1):70-5.

[16] Gupta AK, Chaturvedi SN, Kumar V, et al. Hemiarthroplasty of hip with unipolar and bipolar femoral head prosthesis: a prospective and retrospective evaluation. Indian Journal of Orthopaedics 1994;28(3):12-7.

[17] Novack V, Jotkowitz A, Etzion 0, et al. Does delay in surgery after hip fracture lead to worse outcomes? A multicentre survey. Int $\mathrm{J}$ Qual Health Care 2007;19(3):170-6.

[18] Majumdar SR, Beaupre LA, Johnston DW, et al. Lack of association between mortality and timing of surgery in elderly patients with hip fracture: results of a retrospective population-based cohort study. Med Care 2006;44(6):552-9.

[19] Zhao Y, Fu D, Chen K, et al. Outcome of hemiarthroplasty and total hip replacement for active elderly patients with displaced femoral neck fractures: a meta-analysis of 8 randomized clinical trials. PLoS One 2014;9(5):e98071.

[20] Giannini S, Chiarello E, Cadossi M, et al. Prosthetic surgery in fragility osteopathy. Aging Clin Exp Res 2011;23(2 Suppl):40-2.

[21] Macaulay W, Nellans KW, Garvin KL, et al. Prospective randomized clinical trial comparing hemiarthroplasty to total hip arthroplasty in the treatment of displaced femoral neck fractures: winner of the Dorr award. J Arthroplasty 2008;23(6 Suppl 1):2-8.

[22] Dorr LD, Glousman R, Hoy AL, et al. Treatment of femoral neck fractures with total hip replacement versus cemented and noncemented hemiarthroplasty. J Arthroplasty 1986;1(1):21-8.

[23] Baker RP, Squires B, Gargan MF, et al. Total hip arthroplasty and hemiarthroplasty in mobile, independent patients with a displaced intracapsular fracture of the femoral neck. A randomized, controlled trial. J Bone Joint Surg Am 2006;88(12):2583-9. 